\title{
Silica/alginate hybrid biomaterials and assessment of their covalent coupling
}

\author{
Yuliya Vueva ${ }^{1}$, Louise S. Connell ${ }^{1}$, Slila Chayanun ${ }^{1}$, Daming Wang ${ }^{1}$, David S. McPhail ${ }^{1,2}$, \\ Frederik Romer ${ }^{3}$, John V. Hanna ${ }^{3}$ and Julian R. Jones ${ }^{1 *}$ \\ ${ }^{1}$ Department of Materials, Imperial College London, South Kensington Campus, SW7 2AZ, UK \\ ${ }^{2}$ University of Texas Dallas, Department of Chemistry \& Biochemistry, School of Natural Science \& \\ Mathematics, 800 W Campbell Road, Richardson, TX 75080 USA \\ ${ }^{3}$ Department of Physics, University of Warwick, Gibbet Hill Rd., Coventry CV4 7AL, UK \\ *julian.r.jones@imperial.ac.uk
}

Organic-inorganic hybrid materials composed of co-networks of biodegradable polymer and silica have potential to combine the properties of an elastic organic polymer and inorganic silica. The nanoscale interaction of the co-networks and formation of covalent bonds between them are expected to provide tailored mechanical properties and congruent degradation. Alginate is a natural polymer commonly used in tissue engineering applications due to its good biocompatibility and biodegradability. In this work we present new alginate-silica hybrids prepared through nucleophilic ring opening reaction of 3-glycidoxypropyl trimethoxysilane (GPTMS) by carboxylic groups of alginate and incorporation of this functionalized alginate into the sol-gel process to make a hybrid. The role of the GPTMS is to provide organic/inorganic covalent coupling. The reaction of alginate with GPTMS was followed using NMR, FTIR and ToF-SIMS and the dissolution behaviour, bioactivity and mechanical properties of the resultant alginate-silica hybrid monoliths were evaluated. While mechanical strength was high with values of 110 - $242 \mathrm{MPa}$ comparable to that of cortical bone, the amount of GPTMS coupling to the alginate was low, with the rest of the GPTMS forming diols or a separate network.

Keywords: hybrid; alginate; sol-gel; covalent coupling; biomaterials 


\section{Introduction}

Synthetic materials are needed that can be implanted into bone and cartilage defects and help stimulate natural tissue regeneration. The materials must act as a three dimensional template for tissue growth and ideally be able to share load with the host tissue, before degrading at a controlled rate as the tissue regrows [1]. Current synthetic bone graft substitute materials are bioactive ceramics, such as synthetic hydroxyapatite [2, 3], bioactive glasses [4] and composites [5]. These materials are bioactive, so they can bond with bone, preventing fibrous tissue formation and a stable interface with the host tissue. However, these implants have certain drawbacks. Bioactive glasses and ceramics are brittle, making them unsuitable for implantation in load bearing sites or for cartilage repair.

Polymer-particle composites can overcome the brittle nature of the ceramics. Biocomposites prepared by including calcium phosphate $(\mathrm{CaP})$ particles or bioactive glass particles into biodegradable natural polymers, such as collagen [6], gelatin [7], chitosan [8], alginate [9] or synthetic polyester polymers [5, 10], or into cements [11], have been extensively investigated. However, disadvantages of these composites are the different degradation rates of the components, which can lead to implant instability and the difficulty in maintaining the bioactivity of the particles, as most of them become covered by the polymer, meaning that a high percentage of the particles do not come into contact with the host bone cells.

Given that the bone is a hierarchically structured nanocomposite comprised of hydroxyapatite (HA) nanocrystals dispersed in an organic matrix, it is assumed that biomaterials with similar hierarchical nanocomposite structures can offer improved functional and biological properties in comparison with conventional composites. The interactions between inorganic $(\mathrm{CaP})$ and organic components of bone at molecular or nanoscale level has been shown to influence the behaviour of the bone. For instance, the exceptional toughness of the bone is related to the interactions between the anionic groups of extracellular matrix (ECM) proteins and the calcium ions provided by the inorganic phase [10].

To improve the interaction between organic and organic components, hybrid materials with nanoscale co-networks of silica and organic components, with covalent bonds between the components have been developed [12-22]. Hybrids are synthesized by introducing polymer into the sol-gel process. The silica network forms by the assembly of silica nanoparticles, which 
then grow, coalesce and link together through covalent bonds (via condensation reactions [23, 24]. By introducing a polymer, prior to gelation, the polymer chains can be incorporated. Covalent bonds can form between the polymer and the silica if the polymer is functionalised with silane groups prior to addition to the sol-gel process $[12,16,25]$.

One particular challenge in synthesis of inorganic-organic hybrids for bone implants is the incorporation of calcium ions into the silicate network. The calcium content is important for bioactivity. The calcium incorporation in sol-gel calcium silicate bioactive glasses occurs only upon heating at temperatures higher that $400^{\circ} \mathrm{C}$ [23], which cannot be applied to polymercontaining hybrids. An alternative is to incorporate calcium into the hybrid through chelation with an appropriate biodegradable polymer [20]. Alginate is a naturally occurring polymer composed of blocks of (1-4)-linked $\beta$-D-mannuronic acid (M) and $\alpha$-L-guluronic acid (G) monomers (Figure 1 a). Due to its biocompatibility, biodegradability, non-antigenicity and ability to chelate calcium ions, alginate has been widely used in a variety of biomedical applications including tissue engineering and drug delivery [26-29]. Numerous studies involving the use of alginate-based biomaterials such as alginate-hydroxyapatite [30-32] or alginate-nano bioactive glass composites [33] showed their good potential for bone regeneration applications.

Several reports demonstrated the incorporation of the alginate into the sol-gel process [34-36] however none used covalent coupling between the alginate and silica. Covalent bonding between the co-networks can be achieved by functionalising the polymer with a silane coupling agent that will then bond to the sol-gel silica. Alginate was previously reacted with 3aminopropyl-triethoxysilane (APES), such that the alginate became functionalized with $\mathrm{Si}$-OH groups, which caused cross-linking through condensation. However, no other silicate network precursor (e.g. tetraethylorthosilicate, TEOS) was added, resulting in low silica content and low mechanical properties [37]. 3-Glycidoxypropyl trimethoxysilane (GPTMS) is a coupling agent successfully utilized for hybridization of gelatin [12, 21], poly-glutamic acid [15-17, 20, $38]$ and chitosan [18, 39]. GPTMS contains a reactive epoxy ring, which can undergo acid catalyzed nucleophilic attack, and three methoxysilane groups, which can hydrolyse, forming $\mathrm{Si}-\mathrm{OH}$ groups that can form a network through condensation reactions. Using simple nucleophile molecules (propanol, propyl amine, propanthiol, propanoic acid) and GPTMS in aqueous conditions, at $\mathrm{pH}=5$, it was found that only the carboxylic groups $(-\mathrm{COOH})$ of propanoic acid reacted with GPTMS, forming of ester bonds. [40, 41]. This was later confirmed 
with glutamic acid using solution NMR [42]. A strategy for efficient and controlled scaffold production of such materials is additive manufacturing $[43,44]$.

The aim of this work was to produce a novel hybrid of silica and alginate with covalent coupling between the alginate and a TEOS derived silicate network, using GPTMS. Alginates can be functionalised at the two secondary $-\mathrm{OH}$ positions $(\mathrm{C}-2$ and $\mathrm{C}-3)$ or the one $-\mathrm{COOH}(\mathrm{C}-$ 6) position (Figure $1 \mathrm{a}$ ). We hypothesized that the carboxylic groups of alginate polymer will open the epoxy ring of GPTMS by nucleophilic attack and formation of covalent ester bonding will occur (Figure $1 \mathrm{~b}$ ). The objectives were to investigate the hypothesis of incorporating alginate through covalent coupling with GPTMS into silica gel and to study the potential of the resultant alginate-silica hybrids prepared with different coupling to GPTMS as materials for bone tissue regeneration.

\section{Materials and methods}

\subsection{Materials and samples preparations}

All chemicals were supplied by Sigma Aldrich, UK. For solution NMR experiments, $120 \mathrm{mg}$ sodium alginate was dissolved in $4 \mathrm{ml} 0.01 \mathrm{M} \mathrm{DCl}$ (a deuteration degree of $99.99 \%$ ) at $\mathrm{pH}=5$. 0.01M DCl was prepared by using $20 \% \mathrm{DCl}$, which was diluted in $\mathrm{D}_{2} \mathrm{O}$ (a deuteration degree of $99.99 \%) .83 \mu$ l GPTMS was added to the solution to give an alginate monomer: GPTMS ratio of $2: 1$ and the solution was stirred at $50^{\circ} \mathrm{C}$ for $72 \mathrm{~h} .1 \mathrm{ml}$ aliquots of solution were taken at $12 \mathrm{~h}, 48 \mathrm{~h}$ and $72 \mathrm{~h}$ and placed into NMR tubes. All ${ }^{1} \mathrm{H}$ solution NMR spectra were recorded immediately.

Silica-alginate hybrid monoliths were prepared by dissolving $3 \mathrm{~g}$ sodium alginate in $100 \mathrm{ml}$ $0.01 \mathrm{M} \mathrm{HCl}, \mathrm{pH}=5$ at a concentration $30 \mathrm{mg} / \mathrm{ml}$. Next, a given amount of 3-glycidoxypropyl trimethoxysilane (GPTMS) was added drop-wise to the alginate solution at different sodium alginate monomer: GPTMS ratios (alginate monomer: GPTMS (GC) =0, 2, 5 and 10) and mixed at $50^{\circ} \mathrm{C}$ for $72 \mathrm{~h}$ to functionalize the alginate. Tetraethyl orthosilicate (TEOS) was hydrolyzed by mixing with deionized $\mathrm{H}_{2} \mathrm{O}$ and $1 \mathrm{M} \mathrm{HCl}$ for $1 \mathrm{~h}$. The molar ratio of water: TEOS was 4 and the volume ratio water: $\mathrm{HCl}$ was 3 . The hydrolyzed TEOS was added to the solution of GPTMS-functionalized alginate and left for homogenization and co-condensation for $1 \mathrm{~h}$. All samples were prepared with $50 \mathrm{wt} \%$ alginate and $50 \mathrm{wt} \%$ silica content. Aliquots of $3 \mathrm{ml}$ were taken and put in Teflon moulds and sealed for gelling and aging. The gels were 
aged for three days and slowly dried for up to three weeks at $40^{\circ} \mathrm{C}$.

Some of the hybrids were prepared with additional crosslinking with calcium ions. Gelled samples were immersed in $1 \mathrm{M}$ calcium chloride dihydrate $\left(\mathrm{CaCl}_{2} \cdot 2 \mathrm{H}_{2} \mathrm{O}\right)$ solution and kept at $37^{\circ} \mathrm{C}$ for $24 \mathrm{~h}$. After washing with deionized water, the calcium containing samples were dried slowly in $40^{\circ} \mathrm{C}$ oven for three weeks.

\subsection{Characterization of functionalization reaction by solution state nuclear magnetic resonance (NMR)}

Reaction between alginate and GPTMS was followed by using ${ }^{13} \mathrm{C}$ and ${ }^{1} \mathrm{H}$ one dimensional and two dimensional heteronuclear single quantum coherence (HSQC) experiments. The samples were measured at $298 \mathrm{~K}$ on a Bruker 500MHz AVANCE III HD spectrometer running TopSpin 3.2 and equipped with a z-gradient bbo/5 mm tuneable SmartProbe ${ }^{\mathrm{TM}}$ and a GRASP $\mathrm{II}^{\mathrm{TM}}$ gradient spectroscopy accessory providing a maximum gradient output of $53.5 \mathrm{G} / \mathrm{cm}$ $(5.35 \mathrm{G} / \mathrm{cmA})$.

Proton spectra were acquired at a frequency of $500.13 \mathrm{MHz}$ using a spectral width of $5500 \mathrm{~Hz}$ (centered at $4.5 \mathrm{ppm}$ ) and 32768 data points giving an acquisition time of $3 \mathrm{~s}$. The Bruker pulse programme zg30 (i.e. a $30^{\circ}$ pulse) and relaxation delay of $1 \mathrm{~s}$ were used. The data was processed using 32768 data points.

Carbon spectra were acquired at a frequency of $125.76 \mathrm{MHz}$ using a spectral width of 35714 $\mathrm{Hz}$ (centered at $100 \mathrm{ppm}$ ) and 32768 data points giving an acquisition time of $0.46 \mathrm{~s}$. The Bruker pulse programme zgpg30 (i.e. a $30^{\circ}$ pulse and power gated proton decoupling) and relaxation delay of $1 \mathrm{~s}$ were used. The data was processed using 32768 data points and an exponential window function of $2 \mathrm{~Hz}$.

Quantitative HSQC spectra were acquired using the pulse sequence suggested by Heikkinen $e t$ al. [45]. The directly detected proton dimension used a spectral width of $3001 \mathrm{~Hz}$ (centred at 3 ppm) and 2048 data points giving an acquisition time of $0.34 \mathrm{~s}$. The indirectly detected carbon dimension used a spectral width of $13835 \mathrm{~Hz}$ (centred at $55 \mathrm{ppm}$ ) and 160 experiments collected each with 16 transients (64 transients per experiment in total). A relaxation delay of $5 \mathrm{~s}$ was employed and sine shaped gradients used. Other parameters were taken from the above reference. The indirect dimension was linearly predicted to 256 points, and the data processed using 512 data points for the indirect dimension, 1024 data points for the direct dimension and a cosine squared window function in both dimensions. 


\subsection{Structural characterization of silica-alginate hybrids by solid magic angle spinning (MAS) NMR}

All ${ }^{1} \mathrm{H}-{ }^{13} \mathrm{C}$ cross-polarisation, magic-angle-spinning (CPMAS) NMR data were acquired at 11.7 T using a Bruker Avance III-500 spectrometer operating at ${ }^{1} \mathrm{H}$ and ${ }^{13} \mathrm{C}$ Larmor frequencies of 500.10 and $125.75 \mathrm{MHz}$, respectively. These experiments were conducted using a Bruker 4 mm triple channel (HXY) probe operating in double channel mode in which a sample spinning frequency of $10 \mathrm{kHz}$ was achieved. The initial ${ }^{1} \mathrm{H} \pi / 2$ pulse was $2.5 \mu$ s and the Hartmann-Hahn contact period was $1 \mathrm{~ms}$. The recycle time was $3 \mathrm{~s}$ and the 2400 transients were co-added for the proton decoupling during acquisition was achieved using the SPINAL64 sequence utilising $5 \mu \mathrm{s} \pi$ pulses. Each ${ }^{13} \mathrm{C}$ spectrum was referenced indirectly referenced to tetramethylsilane (TMS, $\delta 0 \mathrm{ppm}$ ) via a secondary solid alanine reference with ${ }^{13} \mathrm{C}$ resonances at $\delta 20.5,51.0$ and 177.9 ppm.

The corresponding ${ }^{29} \mathrm{Si}$ MAS NMR single pulse data were acquired at 7.05 T using a Varian InifinityPlus-300 spectrometer operating at ${ }^{1} \mathrm{H}$ and ${ }^{29} \mathrm{Si}$ Larmor frequencies of 300.10 and 59.59 MHz, respectively. These experiments were undertaken using a Bruker $7 \mathrm{~mm}$ double channel (HX) probe in which a sample spinning frequency of $5 \mathrm{kHz}$ was achieved. The ${ }^{29} \mathrm{Si}$ $\pi / 4$ excitation pulse was of $4 \mu \mathrm{s}$ duration, the recycle time was $240 \mathrm{~s}$ and 1000 transients were co-added. Proton decoupling during data acquisition was achieved using a train of $\pi$ pulses of duration $7.2 \mu$ s with a phase difference of $15^{\circ}$ between subsequent pulses. Each ${ }^{29} \mathrm{Si}$ spectrum was referenced to TMS ( $\delta 0 \mathrm{ppm})$ via a secondary solid kaolinite reference with a resonance at $\delta-92 \mathrm{ppm}$. Spectral simulation/peak fitting of the ${ }^{29} \mathrm{Si}$ MAS NMR data was used to calculate the relative abundance of silica $\mathrm{Q}^{\mathrm{n}}$ and $\mathrm{T}^{\mathrm{n}}$ species. The degree of silica network condensation $\left(\mathrm{D}_{\mathrm{c}}\right)$ was calculated by using the following equation [18]:

$$
\mathrm{D}_{\mathrm{c}}=\frac{2 Q^{2}+3 Q^{3}+4 Q^{4}}{4}+\frac{1 T^{1}+2 T^{2}+3 T^{3}}{3}
$$

Fourier transformation infrared spectroscopy (FTIR) was used to investigate the structure of the hybrids using Thermo Scientific Nicolet iS10 Spectrometer operating in attenuated reflectance mode (ATR). Spectra were taken in the range $450-4000 \mathrm{~cm}^{-1}$ at a resolution of 4 $\mathrm{cm}^{-1}$ and 32 scans. 


\subsection{Characterization of monolith morphology}

The surface morphology of the alginate-silica hybrid monoliths was characterized by scanning electron microscopy (SEM, LEO 1525) equipped with GEMINI field emission column. The SEM operating voltage was $5 \mathrm{kV}$. Samples were prepared for analysis by sputter coating with chromium at $120 \mathrm{~mA}$ for $2 \mathrm{~min}$. The samples were analyzed using a working distance between 6 and $9 \mathrm{~mm}$ and an Inlens secondary detector (SEI) with $30 \mu \mathrm{m}$ aperture.

\subsection{Composition analysis}

Time of flight secondary ion mass spectrometry (ToF-SIMS) was used to determine the distribution of critical elements throughout the monoliths, applying the methods developed in previous work [38]. Prior to the ToF-SIMS analysis, the monoliths were ground and polished down to 4000 grit to obtain a flat sample surface, followed by the further drying at $40{ }^{\circ} \mathrm{C}$ to remove any moisture. A TOF.SIMS 5 instrument (ION-TOF GmbH, Germany) was used.

The samples were sputtered for $1 \mathrm{~s}$ for each scan with a $\mathrm{C}_{60}{ }^{+}$sputter ion beam with a current of $\sim 0.8 \mathrm{nA}$ at $10 \mathrm{keV}$ energy. A sputtered crater of $500 \mu \mathrm{m} \times 500 \mu \mathrm{m}$ was formed. Secondary ion mapping was performed within an area of $300 \mu \mathrm{m} \times 300 \mu \mathrm{m}$ in the sputter crater centre to avoid edge effects, using a $25 \mathrm{keV} \mathrm{Bi}^{+}$primary ion gun of $\sim 1.1 \mathrm{pA}$ with a cycle time of $100 \mu \mathrm{s}$. Each scan provides an image with $256 \times 256$ pixels. Sputtering and surface imaging were alternated, with a total of 460 scans. A low-energy $20 \mathrm{eV}$ pulsed electron flood gun was used for charge compensation.

\subsection{Mechanical properties of the hybrids}

Uni-axial compression tests were performed on cylindrical hybrid monolith samples with a diameter/height ratio 1:1, (mean diameter of $5.5 \mathrm{~mm})(\mathrm{n}=5)$ using Zwick Z010 with $10 \mathrm{~N}$ load cell and compression extension speed $0.5 \mathrm{~mm} \mathrm{~min}^{-1}$.

\subsection{Dissolution and weight loss study}

Bioactivity and dissolution behaviour of the hybrids were studied by immersion in Simulated Body Fluid (SBF) prepared following the Kokubo protocol [46]. Monolith samples were soaked in SBF at an approved ratio of $75 \mathrm{mg}$ : $50 \mathrm{ml}$ in sealed polyethylene containers [47]. The solutions were agitated at $120 \mathrm{rpm}, 37^{\circ} \mathrm{C}$ in an orbital incubator shaker (Newbrunswick 
Scientific - Classic Series C24) and $1 \mathrm{ml}$ solution was removed after 2, 4, 6, 8, 24, 72 and 168 $\mathrm{h}$ and replaced with $1 \mathrm{ml}$ fresh SBF. The solutions were analyzed by inductive coupled plasmaoptical emission spectroscopy (ICP-OES, Thermos iCAP 6300) to determine the concentration of $\mathrm{Si}, \mathrm{Ca}$ and $\mathrm{P}$. Each sample was repeated in triplicate. At the end of the study the samples were removed by filtration and rinsed with acetone to terminate the reaction with SBF and dried at $40^{\circ} \mathrm{C}$ for SEM and XRD analysis.

Weight loss study was performed in TRIS buffer solution at physiological $\mathrm{pH}$ of 7.3. Monoliths (in triplicate) were immersed in TRIS at a ratio $75 \mathrm{mg}: 50 \mathrm{ml}$ and agitated at $120 \mathrm{rpm}$ at $37^{\circ} \mathrm{C}$. Samples were collected at different time points $(24,48,72,168$ and $336 \mathrm{~h})$ by filtration, rinsed with water and dried at $40^{\circ} \mathrm{C}$. Monoliths were weighed before and after immersion in TRIS to calculate the weight loss.

\subsection{Thermal analysis}

In order to determine the organic content remaining in the monoliths, thermal analysis of the samples before and after the dissolution study was performed by thermogravimetric analysis differential scanning calorimeter (NETZSCH STA 449C) using a heating rate of $10^{\circ} \mathrm{C} \mathrm{min}{ }^{-1}$.

\subsection{XRD analysis}

X-ray diffraction was carried out on ground samples using a Bruker AXS D2 Phaser A26-X1A2B0B2B with $\mathrm{Cu}_{\mathrm{Ka}}$ radiation at $40 \mathrm{kV}$ and $40 \mathrm{~mA}$ with a $0.04082 \theta$ step and a count rate of 50 s per step, from $2 \theta$ values of $5^{\circ}$ to $100^{\circ}$.

\section{Results and discussion}

\subsection{GPTMS functionalization reaction}


To investigate the efficacy of the functionalization of alginate with GPTMS, the reaction was performed in $\mathrm{D}_{2} \mathrm{O} / \mathrm{DCl}$ at $\mathrm{pH}=5$ as suggested by Gabrielli et al [40], who found that slightly acidic conditions $(\mathrm{pH}=5)$ are needed in order to functionalize a polymer with GPTMS. When GPTMS is used in aqueous conditions in a reaction involving nucleophilic attack, two competing reactions occurring must be considered: opening of the epoxide ring and hydrolysiscondensation of the $-\mathrm{Si}\left(\mathrm{OCH}_{3}\right)$ groups. At acidic $\mathrm{pH}$ the silanol groups undergo fast hydrolysis followed by condensation and formation of oligomers. The epoxide opening is also favoured at low $\mathrm{pH}$ resulting in diol formation, which is undesired as the sites for potential attack by nucleophiles (the epoxide ring) are reduced. When the $\mathrm{pH}$ is only slightly acidic $(\mathrm{pH}=4-6)$ the diol formation is hypothesized to decrease favouring the functionalization reaction [40, 41].

${ }^{1} \mathrm{H}$ NMR and quantitative ${ }^{13} \mathrm{C}-{ }^{1} \mathrm{H}$ HSQC $2 \mathrm{D}$ NMR experiments were used to follow the reaction at pH 5 as a function of time in situ. After 24 h (Fig. 2) a strong methanol peak was observed $\left(\delta{ }^{1} \mathrm{H} 3.31 \mathrm{ppm}\right)$ indicating fast hydrolysis of the methoxysilane groups. The peaks characteristic to the protons $\mathrm{f} 1$ and $\mathrm{f} 2$ of the epoxy ring $\left(\delta{ }^{1} \mathrm{H} 2.64 \mathrm{ppm} \delta{ }^{1} \mathrm{H} 2.84 \mathrm{ppm}\right)$ decreased in intensity over time, however there was no evidence of reaction between the alginate and GPTMS after $24 \mathrm{~h}$. Instead, formation of diol was observed as new signals appeared ( $\left.\delta^{1} \mathrm{H} 3.46 \mathrm{ppm} \delta{ }^{13} \mathrm{C} 62.59 \mathrm{ppm}\right),\left(\delta{ }^{1} \mathrm{H} 3.52 \mathrm{ppm} \delta{ }^{13} \mathrm{C} 62.59 \mathrm{ppm}\right)$ in the HSQC spectrum (ESI Fig. 1).

HSQC of the functionalization procedure, carried out for $48 \mathrm{~h}$ (Fig. 3) showed new peaks at ( $\delta$ $1 \mathrm{H} 3.55 \mathrm{ppm}, \delta 13 \mathrm{C} 50.42)$, ( $\delta 1 \mathrm{H} 3.62 \mathrm{ppm} \delta 13 \mathrm{C} 50.36 \mathrm{ppm})$ and $(\delta 1 \mathrm{H} 4.05 \mathrm{ppm} \delta 13 \mathrm{C}$ $62.08 \mathrm{ppm}$ ), which were ascribed to the reaction of epoxide ring with carboxylic groups in the alginate. An additional experiment (supplementary information, Fig. S2) investigating the reactivity of GPTMS toward simple alcohol (propanol) showed no reaction occurring between the $-\mathrm{OH}$ groups of the alcohol and GPTMS, thus confirming that the only coupling reaction that have happened was at the carboxylate groups of the alginate. By using quantitative HSQC experiment, we were able to quantify the extent of epoxide ring opening, diol and ester formation. $69 \mathrm{~mol} \%$ of epoxides were unopened after $48 \mathrm{~h}$ of reaction and only $4 \mathrm{~mol} \%$ ester bonds were formed between the alginate and GPTMS, indicating very slow functionalization. Diol formation was predominant as $27 \mathrm{~mol} \%$ was formed, indicating that even at $\mathrm{pH}=5$ the formation of undesired diols is difficult to avoid. Washing the gels in DI water removed unreacted GPTMS and uncondensed diols, but detailed toxicity testing is needed. FTIR of a gelled and aged sample (GC2) confirmed formation of ester bonds as a new peak at $1740 \mathrm{~cm}^{-1}$ 
appeared, which was ascribed to the carbonyl absorption of the ester groups, - COOR (Fig. S3).

\subsection{Structural characterization}

The structure of the silica-alginate hybrids prepared with different coupling to GPTMS was characterized by solid-state ${ }^{13} \mathrm{C}$ and ${ }^{29} \mathrm{Si}$ NMR analysis and ATR FTIR. FTIR spectra of hybrid monoliths (Fig. 4) prepared with different degrees of coupling ( $\mathrm{GC}=0$ to 10$)$ and $50 \mathrm{wt} \%$ organic content showed vibration bands due to Si-O stretching in the silica network $\left(1040 \mathrm{~cm}^{-}\right.$ $\left.{ }^{1}\right)$ and asymmetrical and symmetrical stretching vibrations of $\mathrm{COO}^{-}\left(1620 \mathrm{~cm}^{-1}\right.$ and $1412 \mathrm{~cm}^{-}$ ${ }^{1}$ ) in alginate. The band at $940 \mathrm{~cm}^{-1}$, attributed to the vibration of $\mathrm{Si}-\mathrm{OH}$ groups, was also present in all spectra, and its intensity slightly increased as the amount of GPTMS decreased, indicating a decrease in the degree of condensation of the silica network.

${ }^{29} \mathrm{Si}$ MAS NMR spectra of hybrids prepared with $\mathrm{GC}=2$ to 10 , presented in Fig. 5 revealed two different types of silicate structural units, $\mathrm{Q}^{\mathrm{n}}$ and $\mathrm{T}^{\mathrm{n}}$. $\mathrm{Q}^{\mathrm{n}}$ species represent the pure silica network and give information about the condensation degree in silica, where a $\mathrm{Q}^{\mathrm{n}}$ unit has $\mathrm{n}$ bridging oxygens and 4-n non-bridging oxygens. $\mathrm{T}^{\mathrm{n}}$ species describe silicon atoms condensed in a silica network and also bonded to a carbon atom. The spectrum contains five different resonance peaks, three of which are indicated as $\mathrm{Q}^{4}\left[\mathrm{Si}(\mathrm{OSi})_{4}\right], \mathrm{Q}^{3}\left[(\mathrm{OH}) \mathrm{Si}(\mathrm{OSi})_{3}\right]$ and $\mathrm{Q}^{2}$ $\left[(\mathrm{OH})_{2} \mathrm{Si}(\mathrm{OSi})_{2}\right]$ and the other two designated as $\mathrm{T}^{3}\left[(\mathrm{SiO})_{3} \mathrm{SiC}\right]$ and $\mathrm{T}^{2}\left[(\mathrm{SiO})_{2}(\mathrm{OH}) \mathrm{SiC}\right][48]$. Increasing the molar ratio of GPTMS to alginate increased the intensity of $\mathrm{T}$ species and decreased the intensity of $\mathrm{Q}$ species, as the amount of TEOS used in the synthesis was decreased at the expense of GPTMS in order to keep the ratio organic: inorganic constant (50:50). For the sample prepared with GC 10, the concentration of the T species was too low to be detected by the instrument. By using peak fitting the percentage abundance of $\mathrm{Q}$ and $\mathrm{T}$ species was quantified and condensation degree of silica network was calculated (Table 1).

The condensation degree increased slightly from $87 \%$ for the sample with GC $=5$ to $89 \%$ for the GC = 2 sample as the amount of GPTMS increased, supporting the FTIR data. This indicated that at the highest GC, the silica network of the hybrid was composed predominantly of $\mathrm{Q}^{4}$ and $\mathrm{T}^{3}$ species with less non-bridging silica-oxygen bonds ( $\left.\mathrm{Si}-\mathrm{OH}\right)$.

${ }^{13} \mathrm{C}$ CP NMR spectrum (Fig. 6) of aged and dried samples with GC $=2$ (50 wt \% organic) revealed resonances characteristic of alginate polymer and GPTMS. As the spectrum is very 
saturated with resonances in the range $50-120 \mathrm{ppm}$ due to many different C-O species it was difficult to assign the resonances in this region.

An additional peak at $172 \mathrm{ppm}$, which is characteristic of the carboxylic ester groups, is evidence of reaction of alginate with GPTMS, supporting the liquid NMR data. We cannot exclude the possibility that the functionalization reaction continued during the aging through drying steps. The water content during drying becomes insignificant, thus favouring the reaction of nucleophilic attack and ester bond formation rather than diol formation.

\subsection{Compositional analysis}

ToF-SIMS was used to determine the distribution of silicon and calcium (silicon and calcium are critical elements in development of bioactive materials for bone regeneration as they are responsible for stimulation of osteogenic cells [49]) within the hybrid monoliths prepared with calcium chloride.

Figure 7 (a) and (b) illustrate secondary $\mathrm{Ca}^{+}$and $\mathrm{Si}^{+}$ion distributions for a sample prepared without coupling to GPTMS. $\mathrm{Ca}^{+}$was homogeneously distributed within the alginate network, suggesting successful chelation with the $-\mathrm{COO}^{-}$groups. In contrast, $\mathrm{Si}^{+}$was heterogeneously distributed, showing poor dispersion of the silica sol within the alginate solution, when the hybrid was prepared without covalent coupling. The ToF-SIMS images (Fig. 7 (c) and (d)) of a sample prepared with covalent coupling to GPTMS $(\mathrm{GC}=10)$ showed heterogeneous distribution profiles of both $\mathrm{Ca}$ and $\mathrm{Si}$ ions. However, the profiles appeared to be very similar. The maximum concentration of $\mathrm{Ca}^{+}$appeared in the same location as that of $\mathrm{Si}^{+}$, implying that the species are interacting closely. This could be considered as indirect evidence of successful functionalization of alginate with GPTMS. Since the calcium was chelated to the free $-\mathrm{COO}^{-}$ groups of alginate, this is further evidence that GTPMS was bound to alginate via ester bonds. It can be concluded that the silica network was cross linked with alginate/Ca with the addition of GPTMS. Therefore, we may suggest that GPTMS is the key to a silica network to alginate to form a hybrid. The heterogeneous distribution of the elements is most likely due to the formation of two silica networks during the sol-gel reaction, consisting of not fully cocondensed GPTMS and TEOS oligomer chains. In fact this is difficult to overcome, as the functionalization process requires at least $48 \mathrm{~h}$ functionalization reaction in aqueous conditions and acidic $\mathrm{pH}$ leading to partial co-condensation of GPTMS molecules (formation of -Si-O-Sibonds), which will not integrate within the silica network provided by TEOS in the subsequent step of the hybrid fabrication. This assumption is in agreement with the data obtained 
previously by Connell et al. in a study of the reaction between chitosan and GPTMS [18]. The authors found that at acidic conditions $(\mathrm{pH}=2)$ within $5 \mathrm{~min}$, the condensation reaction occurred between the hydrolyzed GPTMS monomers, and up to 60\% of GPTMS was present in a $\mathrm{T}^{3}$ form. This renders that part of GPTMS a separate silica network.

\subsection{Dissolution study and bioactivity}

Dissolution profiles ( $\mathrm{Si}, \mathrm{Ca}$ and $\mathrm{P}$ ) for hybrid samples prepared with $\mathrm{GC}=0,2,5,10$ and calcium in SBF solution as a function of time are shown in Fig. 8. For all samples, the concentration of silicon (Fig. 8a) in SBF increased over time showing the dissolution of the silica network. Initially, the silicon concentration profile (up to $8 \mathrm{~h}$ ) showed that the sample with $\mathrm{GC}=0$ released silicon faster than the GPTMS - functionalized samples. However, after $24 \mathrm{~h}$ in SBF, the GC2 sample started to release silicon faster than the others, reaching a plateau after one week with the highest silicon concentration of $96 \mu \mathrm{g} / \mathrm{ml}$. The sample without GPTMS reached a plateau after $72 \mathrm{~h}$ and had the lowest final silicon concentration of $59 \mu \mathrm{g} / \mathrm{ml}$.

The rapid silicon release from samples prepared with highest amount of GPTMS could be explained by the assumption that increasing GPTMS resulted in poor co-condensation between GPTMS and TEOS, and the inorganic content contained domains of condensed GPTMS and the silica network that originated from TEOS with Si-OH sites more easily accessible to the attack of the $\mathrm{H}_{2} \mathrm{O}$ molecules. Another possible explanation could be due to fact that a portion of GPTMS epoxide groups converted into diols, making the silica network more hydrophilic and more susceptible to the attack by water. 
The calcium release profiles shown in Fig. $8 \mathrm{~b}$ indicated that all the samples released chelated calcium ions rapidly in the first hours of immersion in SBF. Phosphorous content remained approximately constant, indicating that no hydroxyapatite was formed after one week in SBF. However, the surface analysis of the monoliths by SEM (and subsequent confirmation by XRD) showed hydroxyapatite (HA) deposits formed within four weeks in SBF solution (Fig. 9). This may be too long to be considered truly bioactive.

Previous studies on natural and synthetic polymers reported that apatite deposition could be initiated by carboxylic functional groups that exist on the surface of the material $[36,37]$. For this reason, polyuronic acids such as alginate have the potential to induce hydroxyapatite formation on the surface in SBF. However, most of the carboxylic groups of alginate are engaged in egg-box-like structures by chelation of calcium ions and some of the carboxylic groups are converted into ester groups after reaction with GPTMS. Therefore, silanol functional groups, which also can act as sites for apatite nucleation, would be the most likely nucleation sites for HA formation [50]. Apatite formation has also been observed on chitosan/silica hybrids, which do not contain carboxylic groups, in SBF [51, 52]. The slow HA deposition of the silica-alginate materials could be associated with the longer time needed for degradation of the hybrid silica network and for formation of Si-OH rich layer on the surface, compared to conventional sol-gel bioactive glasses, where the fast degradation of the silicate glass network is due to rapid exchange of $\mathrm{Ca}^{2+}$ with $\mathrm{H}^{+}$from the $\mathrm{SBF}$ [1].

Dissolution behaviour of silica-alginate hybrids prepared with and without GPTMS and calcium ions was studied in TRIS buffer solution at physiological $\mathrm{pH}=7.4$.

The weight loss graph shows that the samples (GC0 and GC0 Ca) prepared without GTPMS, lost weight more rapidly than the $\mathrm{GC}=10$ samples (Figure 10). They lost most of their mass in the first $24 \mathrm{~h}$ and then the rate of degradation was low. Without functionalization with GPTMS, alginate polymer was only trapped within the silica network through hydrogen bonding or other unspecific weak interactions and was easily released upon immersion in, which is one of the characteristic features of Class I hybrid materials [53]. Once the alginate polymer had dissolved, the rate of loss of the material became steady due to the slow dissolution of the silica gel. Samples functionalized with GPTMS showed more continuous dissolution over time with a slower initial rate, thus suggesting that some covalent coupling did occur between alginate 
and GPTMS, preventing rapid release of the polymer on immersion. When the sample was prepared with calcium ions the dissolution rate increased.

FTIR spectra of the hybrids immersed in TRIS buffer solution for two weeks (Fig. 11) confirmed the complete loss of the alginate for the samples with $\mathrm{GC}=0$, as the bands characteristic of the carboxylate functionality were no longer present. Samples prepared with $\mathrm{GC}=10$ showed a decrease in intensity of both alginate and $\mathrm{Si}-\mathrm{OH}$ bands. This was also confirmed by DSC-TG analysis (Fig. S4).

\subsection{Mechanical properties}

Fig. 12 shows characteristic stress - strain curves of silica / alginate hybrid monoliths and solgel $70 \mathrm{~mol} \% \mathrm{SiO}_{2} 30 \mathrm{~mol} \% \mathrm{CaO}$ (70S30C) glass obtained in uniaxial compression. All hybrid monoliths showed an improved compressive strength and strain compared to 70S30C (70 $\mathrm{mol} \% \mathrm{SiO}_{2}, 30 \mathrm{~mol} \% \mathrm{CaO}$ ) bioactive glass. The strain to failure increased from $4.5 \%$ for the sol-gel 70S30C glass to 12.7 - $18.8 \%$ for the hybrid samples (Table 2), indicating reduced brittleness. The compressive strength of the hybrid monoliths was also higher 110-242 $\mathrm{MPa}$, compared to $89 \mathrm{MPa}$ of the bioactive glass. Increasing the covalent coupling increased the strain to failure and resulted in slight reduction of the compressive strength. These results confirmed that the interaction at molecular level through covalent bonding improved the mechanical properties of the two components compared to the bioactive glass and the sample prepared without coupling (GC0). Although the obtained compressive strengths of the hybrid monoliths are very similar to that of the cortical bone (100 - $230 \mathrm{MPa})$, the values would be lower for porous scaffolds. However, the silica-alginate hybrids showed to be promising in terms of their strain to failure.

\section{Conclusions}

In this work, for the first time, we report the incorporation of alginate polymer within a silica network through covalent coupling with GPTMS. By using different analytical techniques e.g. liquid and solid state NMR, FTIR and ToF-SIMS, we have demonstrated that the reaction between the epoxide ring of GPTMS and carboxylic acid groups of alginate occurred. However, due to the dual reactivity of GPTMS in water, where two competing reactions occur at the same time (diol formation and GPTMS hydrolysis and condensation), it was difficult to 
achieve a high degree of coupling. Quantitative HSQC experiment has shown that the predominant reaction in the first $48 \mathrm{~h}$ of the functionalization of alginate with GPTMS was GTPMS-diol formation, while the ester bond formation was low. Hydrolysis of the methoxysilane groups of GPTMS also occurred quickly, indicated by the large amount of methanol formed in the first hours. Once hydrolyzed, GPTMS quickly undergoes condensation in acidic conditions resulting in formation of $-\mathrm{Si}-\mathrm{O}-\mathrm{Si}$ - network. This could explain the poor integration of GPTMS in the silica network provided by TEOS in the subsequent step of production of the hybrids as ToF-SIMS analysis has shown silicon ion inhomogeneity. A dissolution study also supported this assumption, as the material produced with the highest content of GPTMS showed the fastest rate of silica release in SBF solution.

However, it is very likely that the functionalization reaction continues during the drying-aging step. The aged and/or dried monoliths prepared with coupling to GPTMS showed more integrated properties compared to the monoliths without GPTMS. The hybrids had continuous and slower degradation in time, improved mechanical properties in terms of compressive strength and strain to failure, and bioactivity thus showing promise for bone tissue application. However, an alternative coupling method may yield even more improved mechanical properties. The tailorability of the hybrids through the alginate content and degree of coupling mean that they have potential for bone and cartilage regeneration applications.

\section{Acknowledgements}

Yuliya Vueva held a Marie-Curie Intra-European Fellowship funded by European Union's FP7 research and innovation programme, grant agreement No. 299598. JVH acknowledges support for the solid state NMR facilities at Warwick used in this research which were funded by EPSRC and the University of Warwick, with additional partial funding being provided through the Birmingham Science City AM1 and AM2 projects which were supported by Advantage West Midlands (AWM) and the European Regional Development Fund (ERDF). JVH also acknowledges EPSRC support for FR via project EP/I004688/1.

\section{References}

[1] J.R. Jones, Review of bioactive glass: From Hench to hybrids, Acta Biomater 9 (2013) 4457-86.

[2] R.Z. LeGeros, Properties of osteoconductive biomaterials: Calcium phosphates, Clin Orthop Rel Res (2002) 81-98. 
[3] W. Habraken, P. Habibovic, M. Epple, M. Bohner, Calcium phosphates in biomedical applications: materials for the future?, Mater Today 19 (2016) 69-87.

[4] J.R. Jones, D.S. Brauer, L. Hupa, D.C. Greenspan, Bioglass and Bioactive Glasses and Their Impact on Healthcare, International Journal of Applied Glass Science 7 (2016) 42334.

[5] K. Rezwan, Q.Z. Chen, J.J. Blaker, A.R. Boccaccini, Biodegradable and bioactive porous polymer/inorganic composite scaffolds for bone tissue engineering, Biomaterials 27 (2006) 3413-31.

[6] C.Z. Liu, Z.W. Han, J.T. Czernuszka, Gradient collagen/nanohydroxyapatite composite scaffold: Development and characterization, Acta Biomater 5 (2009) 661-9.

[7] M.B. Yaylaoglu, P. Korkusuz, U. Ors, F. Korkusuz, V. Hasirci, Development of a calcium phosphate-gelatin composite as a bone substitute and its use in drug release, Biomaterials 20 (1999) 711-9.

[8] Y. Zhang, M.Q. Zhang, Synthesis and characterization of macroporous chitosan/calcium phosphate composite scaffolds for tissue engineering, J Biomed Mater Res 55 (2001) 304-12.

[9] J.H. Park, E.J. Lee, J.C. Knowles, H.W. Kim, Preparation of in situ hardening composite microcarriers: Calcium phosphate cement combined with alginate for bone regeneration, J Biomater Appl 28 (2014) 1079-84.

[10] K. Farbod, M.R. Nejadnik, J.A. Jansen, S.C.G. Leeuwenburgh, Interactions Between Inorganic and Organic Phases in Bone Tissue as a Source of Inspiration for Design of Novel Nanocomposites, Tissue Eng Part B 20 (2014) 173-88.

[11] Z. Ruan, D. Yao, Q. Xu, L. Liu, Z. Tian, Y. Zhu, Effects of mesoporous bioglass on physicochemical and biological properties of calcium sulfate bone cements, Applied Materials Today 9 (2017) 612-21.

[12] O. Mahony, O. Tsigkou, C. Ionescu, C. Minelli, L. Ling, R. Hanly, M.E. Smith, M.M. Stevens, J.R. Jones, Silica-Gelatin Hybrids with Tailorable Degradation and Mechanical Properties for Tissue Regeneration, Adv Funct Mater 20 (2010) 3835-45.

[13] M.M. Pereira, J.R. Jones, R.L. Orefice, L.L. Hench, Preparation of bioactive glasspolyvinyl alcohol hybrid foams by the sol-gel method, J Mater Sci - Mater Med 16 (2005) 1045-50.

[14] Y. Shirosaki, T. Okayama, K. Tsuru, S. Hayakawa, A. Osaka, Synthesis and cytocompatibility of porous chitosan-silicate hybrids for tissue engineering scaffold application, Chem Eng J 137 (2008) 122-8.

[15] G. Poologasundarampillai, C. Ionescu, O. Tsigkou, M. Murugesan, R.G. Hill, M.M. Stevens, J.V. Hanna, M.E. Smith, J.R. Jones, Synthesis of bioactive class II poly(gammaglutamic acid)/silica hybrids for bone regeneration, J Mater Chem 20 (2010) 8952-61.

[16] G. Poologasundarampillai, B. Yu, O. Tsigkou, E.M. Valliant, S. Yue, P.D. Lee, R.W. Hamilton, M.M. Stevens, T. Kasuga, J.R. Jones, Bioactive silica-poly(g-glutamic acid) hybrids for bone regeneration: effect of covalent coupling on dissolution and mechanical properties and fabrication of porous scaffolds, Soft Matter 8 (2012) 4822-32

[17] G. Poologasundarampillai, B. Yu, O. Tsigkou, D. Wang, F. Romer, V. Bhakhri, F. Giuliani, M.M. Stevens, D.S. McPhail, M.E. Smith, J.V. Hanna, J.R. Jones, Poly(gammaglutamic acid)/silica hybrids with calcium incorporated in the silica network by use of a calcium alkoxide precursor, Chem Eur J 20 (2014) 8149-60.

[18] L.S. Connell, F. Romer, M. Suarez, E.M. Valliant, Z.Y. Zhang, P.D. Lee, M.E. Smith, J.V. Hanna, J.R. Jones, Chemical characterisation and fabrication of chitosan-silica hybrid scaffolds with 3-glycidoxypropyl trimethoxysilane, J Mat Chem B 2 (2014) 668-80. 
[19] S.H. Rhee, Y.K. Lee, B.S. Lim, Evaluation of a novel poly(epsilon-caprolactone)organosiloxane hybrid material for the potential application as a bioactive and degradable bone substitute, Biomacromolecules 5 (2004) 1575-9.

[20] E.M. Valliant, F. Romer, D. Wang, D.S. McPhail, M.E. Smith, J.V. Hanna, J.R. Jones, Bioactivity in silica/poly(gamma-glutamic acid) sol-gel hybrids through calcium chelation, Acta Biomater 9 (2013) 7662-71.

[21] O. Mahony, S. Yue, C. Turdean-Ionescu, J.V. Hanna, M.E. Smith, P.D. Lee, J.R. Jones, Silica-gelatin hybrids for tissue regeneration: inter-relationships between the process variables, J Sol-Gel Sci Technol 69 (2014) 288-98.

[22] K. Tsuru, S. Hayakawa, A. Osaka, Synthesis of bioactive and porous organic-inorganic hybrids for biomedical applications, J Sol-Gel Sci Technol 32 (2004) 201-5.

[23] S. Lin, C. Ionescu, K.J. Pike, M.E. Smith, J.R. Jones, Nanostructure evolution and calcium distribution in sol-gel derived bioactive glass, J Mater Chem 19 (2009) 1276-82. [24] V. FitzGerald, R.A. Martin, J.R. Jones, D. Qiu, K.M. Wetherall, R.M. Moss, R.J. Newport, Bioactive glass sol-gel foam scaffolds: Evolution of nanoporosity during processing and in situ monitoring of apatite layer formation using small- and wide-angle X-ray scattering, J Biomed Mater Res Part A 91A (2009) 76-83.

[25] S.H. Rhee, J.Y. Choi, H.M. Kim, Preparation of a bioactive and degradable poly(epsilon-caprolactone)/silica hybrid through a sol-gel method, Biomaterials 23 (2002) 4915-21.

[26] K.I. Draget, G. SkjakBraek, O. Smidsrod, Alginate based new materials, Int J Biol Macromol 21 (1997) 47-55.

[27] J.C. Sun, H.P. Tan, Alginate-Based Biomaterials for Regenerative Medicine Applications, Materials 6 (2013) 1285-309.

[28] N. Bhattarai, Z.S. Li, D. Edmondson, M.Q. Zhang, Alginate-based nanofibrous scaffolds: Structural, mechanical, and biological properties, Adv Mater 18 (2006) 1463-+. [29] A.D. Augst, H.J. Kong, D.J. Mooney, Alginate hydrogels as biomaterials, Macromolecular Bioscience 6 (2006) 623-33.

[30] Y.X. Luo, A. Lode, F. Sonntag, B. Nies, M. Gelinsky, Well-ordered biphasic calcium phosphate-alginate scaffolds fabricated by multi-channel 3D plotting under mild conditions, J Mat Chem B 1 (2013) 4088-98.

[31] A. Tampieri, M. Sandri, E. Landi, G. Celotti, N. Roveri, M. Mattioli-Belmonte, L. Virgili, F. Gabbanelli, G. Biagini, HA/alginate hybrid composites prepared through bio-inspired nucleation, Acta Biomater 1 (2005) 343-51.

[32] Y.Y. Jiang, Y.J. Zhu, H. Li, Y.G. Zhang, Y.Q. Shen, T.W. Sun, F. Chen, Preparation and enhanced mechanical properties of hybrid hydrogels comprising ultralong hydroxyapatite nanowires and sodium alginate, Journal of Colloid and Interface Science 497 (2017) 266-75.

[33] S. Srinivasan, R. Jayasree, K.P. Chennazhi, S.V. Nair, R. Jayakumar, Biocompatible alginate/nano bioactive glass ceramic composite scaffolds for periodontal tissue regeneration, Carbohydrate Polymers 87 (2012) 274-83.

[34] N. Nassif, O. Bouvet, M.N. Rager, C. Roux, T. Coradin, J. Livage, Living bacteria in silica gels, Nature Mater 1 (2002) 42-4.

[35] M. Boissiere, J. Allouche, C. Chaneac, R. Brayner, J.M. Devoisselle, J. Livage, T. Coradin, Potentialities of silica/alginate nanoparticles as hybrid magnetic carriers, International Journal of Pharmaceutics 344 (2007) 128-34.

[36] M. Blondeau, T. Coradin, Living materials from sol-gel chemistry: current challenges and perspectives, J Mater Chem 22 (2012) 22335-43. 
[37] K. Hosoya, C. Ohtsuki, T. Kawai, M. Kamitakahara, S. Ogata, T. Miyazaki, M. Tanihara, A novel covalently crosslinked gel of alginate and silane with the ability to form bone-like apatite, J Biomed Mater Res Part A 71A (2004) 596-601.

[38] D. Wang, J. Nakamura, G. Poologasundarampillai, T. Kasuga, J.R. Jones, D.S. McPhail, ToF-SIMS evaluation of calcium-containing silica/gamma-PGA hybrid systems for bone regeneration, Applied Surface Science 309 (2014) 231-9.

[39] Y. Shirosaki, K. Tsuru, S. Hayakawa, A. Osaka, M.A. Lopes, J.D. Santos, M.A. Costa, M.H. Fernandes, Physical, chemical and in vitro biological profile of chitosan hybrid membrane as a function of organosiloxane concentration, Acta Biomater 5 (2009) 346-55.

[40] L. Gabrielli, L. Russo, A. Poveda, J.R. Jones, F. Nicotra, J. Jimenez-Barbero, L. Cipolla, Epoxide Opening versus Silica Condensation during Sol-Gel Hybrid Biomaterial Synthesis, Chem Eur J 19 (2013) 7856-64.

[41] L. Gabrielli, L. Connell, L. Russo, J. Jimenez-Barbero, F. Nicotra, L. Cipolla, J.R. Jones, Exploring GPTMS reactivity against simple nucleophiles: chemistry beyond hybrid materials fabrication, RSC Adv 4 (2014) 1841-8.

[42] L.S. Connell, L. Gabrielli, O. Mahony, L. Russo, L. Cipolla, J.R. Jones, Functionalizing natural polymers with alkoxysilane coupling agents: reacting 3-glycidoxypropyl trimethoxysilane with poly(gamma-glutamic acid) and gelatin, Polym Chem 8 (2017) 1095-103.

[43] J.-Y. Lee, J. An, C.K. Chua, Fundamentals and applications of 3D printing for novel materials, Applied Materials Today 7 (2017) 120-33.

[44] C. Gao, M.N. Rahaman, Q. Gao, A. Teramoto, K. Abe, Robotic deposition and in vitro characterization of 3D gelatinbioactive glass hybrid scaffolds for biomedical applications, J Biomed Mater Res Part A 101 (2013) 2027-37.

[45] S. Heikkinen, M.M. Toikka, P.T. Karhunen, I.A. Kilpelainen, Quantitative 2D HSQC (QHSQC) via suppression of J-dependence of polarization transfer in NMR spectroscopy: Application to wood lignin, JACS 125 (2003) 4362-7.

[46] T. Kokubo, H. Kushitani, S. Sakka, T. Kitsugi, T. Yamamuro, Solution able to reproduce in vivo surface-structure in bioactive glass-ceramic A-W3, J Biomed Mater Res 24 (1990) 721-34.

[47] A.L.B. Macon, T.B. Kim, E.M. Valliant, K. Goetschius, R.K. Brow, D.E. Day, A. Hoppe, A.R. Boccaccini, I.Y. Kim, C. Ohtsuki, T. Kokubo, A. Osaka, M. Vallet-Regi, D. Arcos, L. Fraile, A.J. Salinas, A.V. Teixeira, Y. Vueva, R.M. Almeida, M. Miola, C. Vitale-Brovarone, E. Verne, W. Hoeland, J.R. Jones, A unified in vitro evaluation for apatite-forming ability of bioactive glasses and their variants, J Mater Sci - Mater Med 26 (2015) 115-.

[48] K.J.D. MacKenzie, M.E. Smith, Multinuclear solid state NMR of inorganic materials. Pergamon Press, Oxford, 2002.

[49] L.L. Hench, J.M. Polak, Third-generation biomedical materials, Science 295 (2002) 1014-7.

[50] P.J. Li, C. Ohtsuki, T. Kokubo, K. Nakanishi, N. Soga, K. Degroot, The role of hydrated silica, titania, and alumina in inducing apatite on implants, J Biomed Mater Res 28 (1994) 7-15.

[51] Y. Shirosaki, K. Tsuru, S. Hayakawa, A. Osaka, M.A. Lopes, J.D. Santos, M.H. Fernandes, In vitro cytocompatibility of MG63 cells on chitosan-organosiloxane hybrid membranes, Biomaterials 26 (2005) 485-93.

[52] Y. Shirosaki, K. Tsuru, H. Moribayashi, S. Hayakawa, Y. Nakamura, I.R. Gibson, A. Osaka, Preparation of osteocompatible Si(IV)-enriched chitosan-silicate hybrids, J Ceram Soc Jpn 118 (2010) 989-92. 
[53] C. Sanchez, P. Belleville, M. Popall, L. Nicole, Applications of advanced hybrid organicinorganic nanomaterials: from laboratory to market, Chem Soc Rev 40 (2011) 696-753. 
Figure Captions

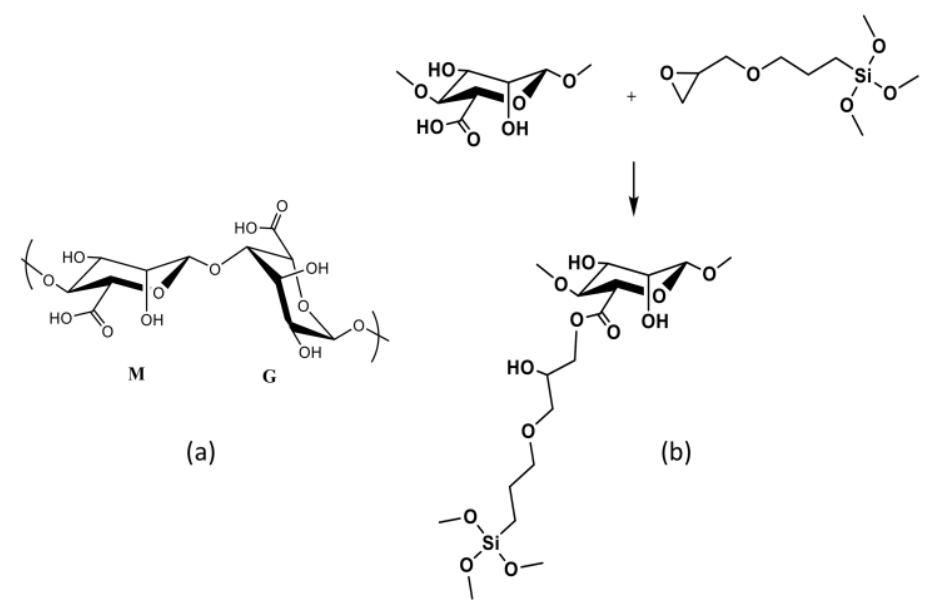

Fig. 1 (a) Representative alginate structure; (b) Scheme of the reaction of alginate with GPTMS.

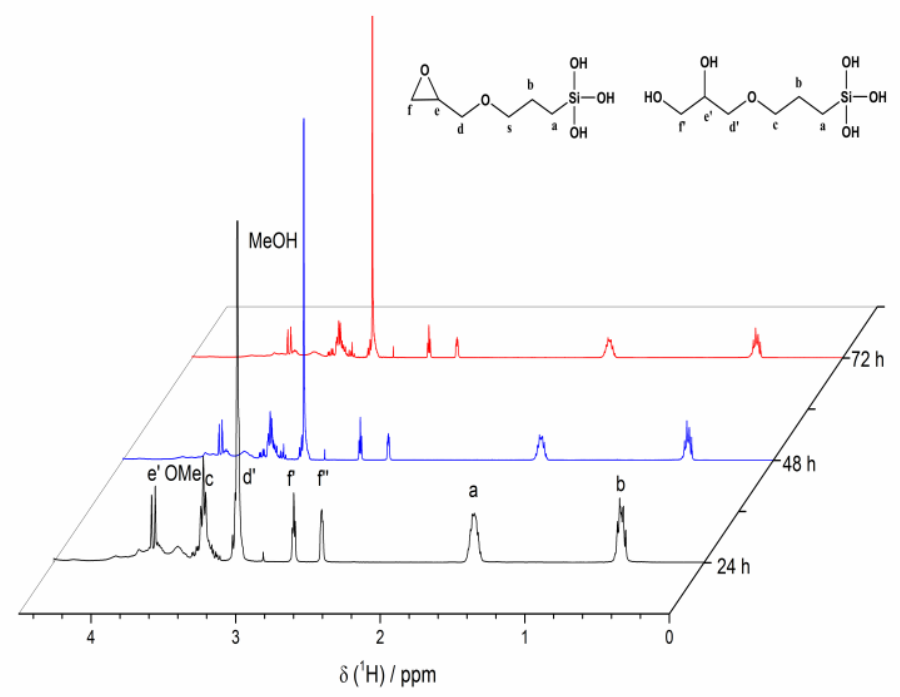

Fig. 2 Liquid state ${ }^{1} \mathrm{H}$ NMR of alginate and GPTMS in $\mathrm{D}_{2} \mathrm{O}, \mathrm{pH}=5$ at different time points. 


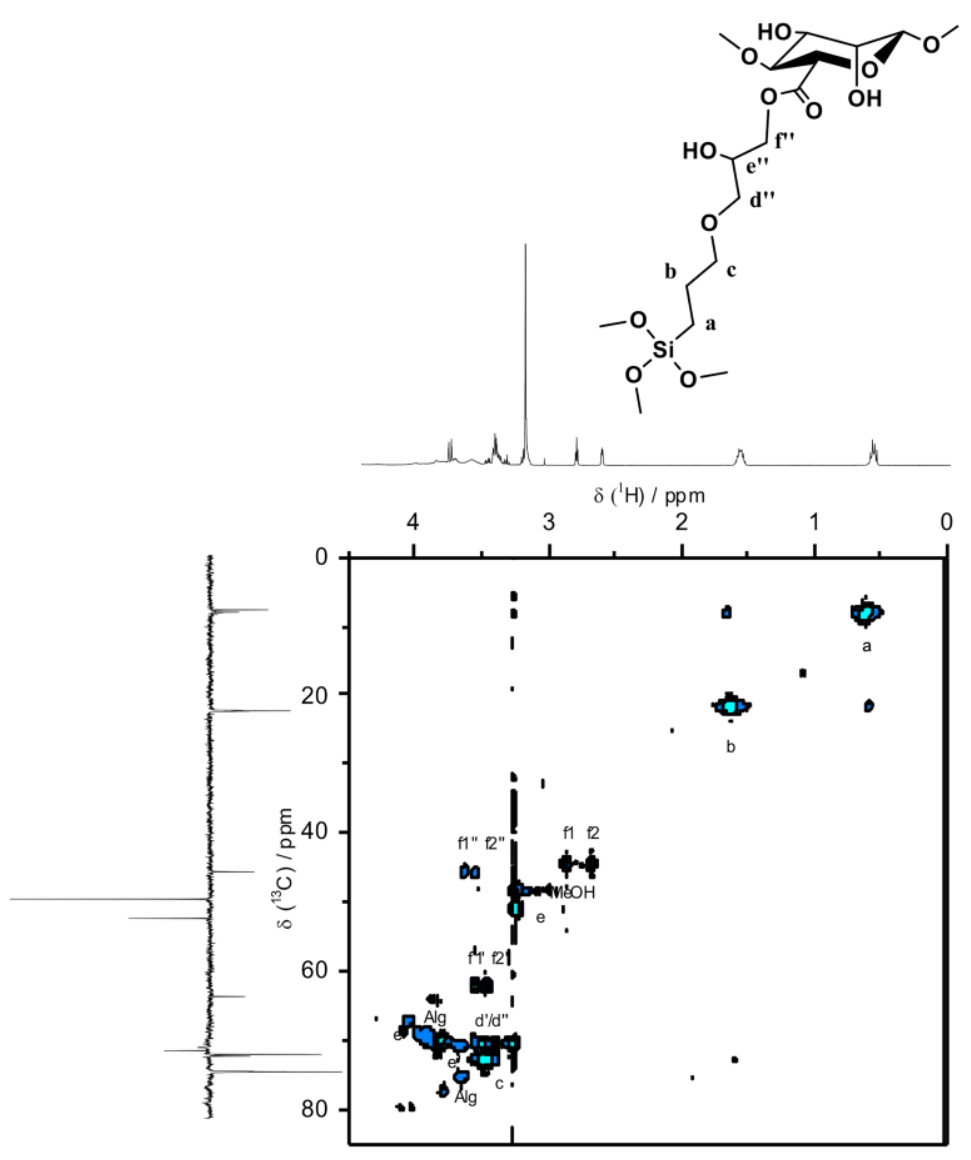

Fig. 3 Quantitative ${ }^{1} \mathrm{H}_{-}{ }^{13} \mathrm{C}$ HSQC NMR spectrum of alginate functionalized with GPTMS for 48 h. 


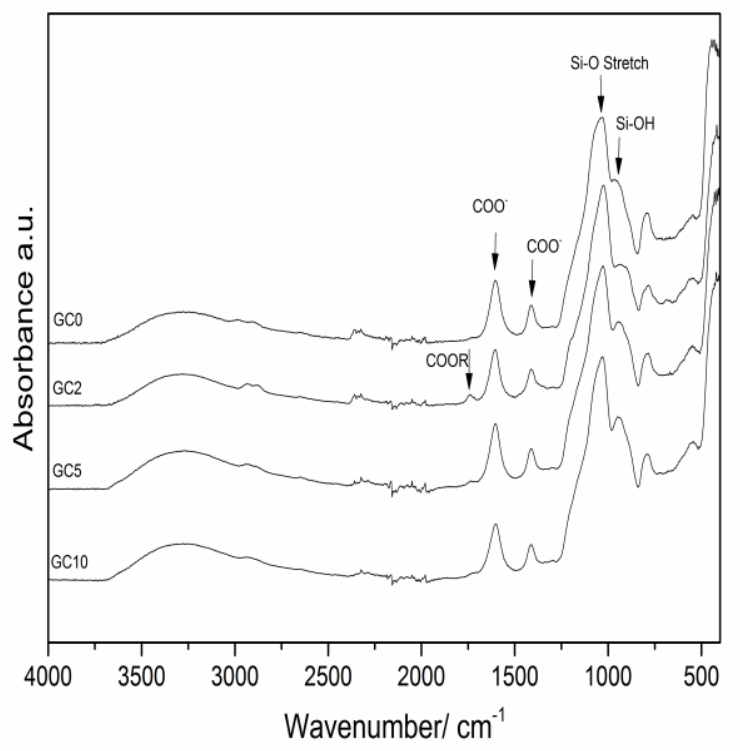

Fig. 4 FTIR spectra of hybrid monoliths with $50 \mathrm{wt} \%$ organic content and different ratios of alginate units : $\mathrm{GPTMS}(\mathrm{GC}=0,2,5,10)$. 


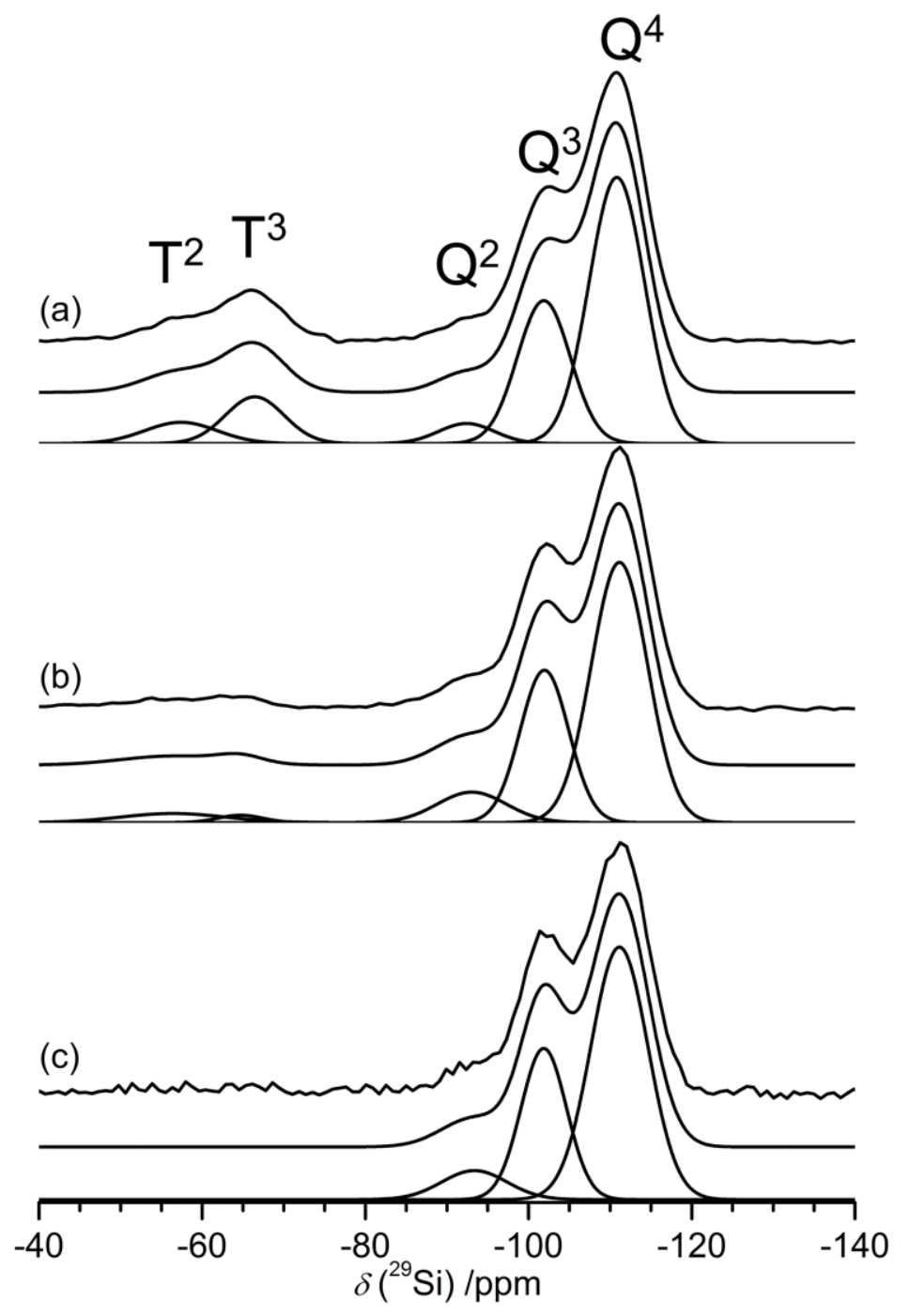

Fig. $5{ }^{29} \mathrm{Si}$ MAS NMR spectra, and their peak fitting, from hybrid systems synthesized with $50 \mathrm{wt} \%$ organic content and (a) $\mathrm{CG}=2$, (b) $\mathrm{CG}=5$ and (c) $\mathrm{CG}=10$. 


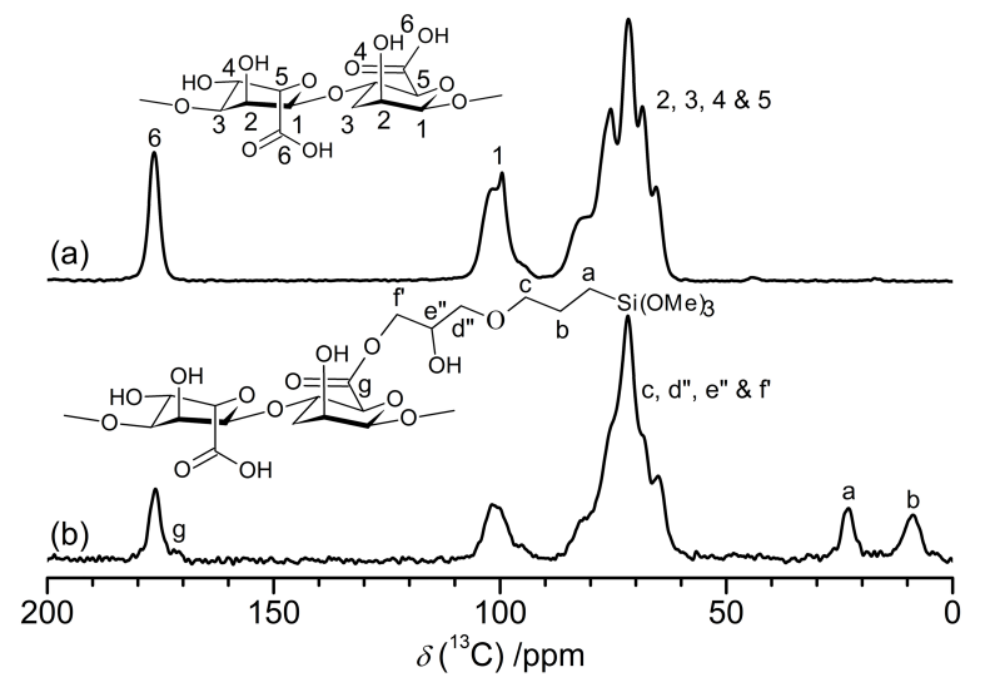

Fig. $6{ }^{13} \mathrm{C}$ CPMAS NMR data from (a) alginate and (b) a hybrid system prepared with $50 \mathrm{wt}$ $\%$ alginate and $\mathrm{GC}=2$. 


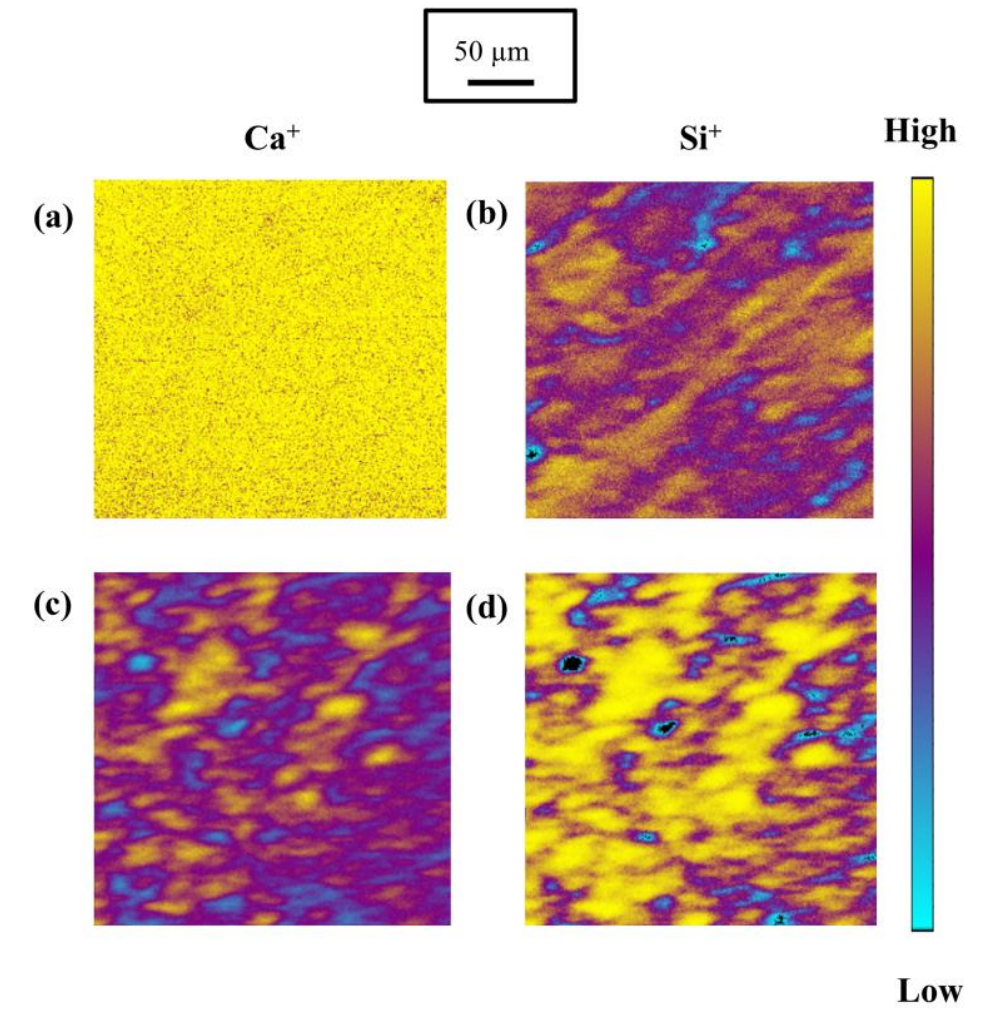

Fig. 7 ToF-SIMS images of hybrids containing calcium: (a) $\mathrm{Ca}^{+}$and (b) $\mathrm{Si}^{+}$of a sample with $\mathrm{GC}=0$ and $50 \mathrm{wt} \%$ organic content; (c) $\mathrm{Ca}^{+}$and (d) $\mathrm{Si}^{+}$of a sample with $\mathrm{GC}=10$ and $50 \mathrm{wt} \%$ organic content. 


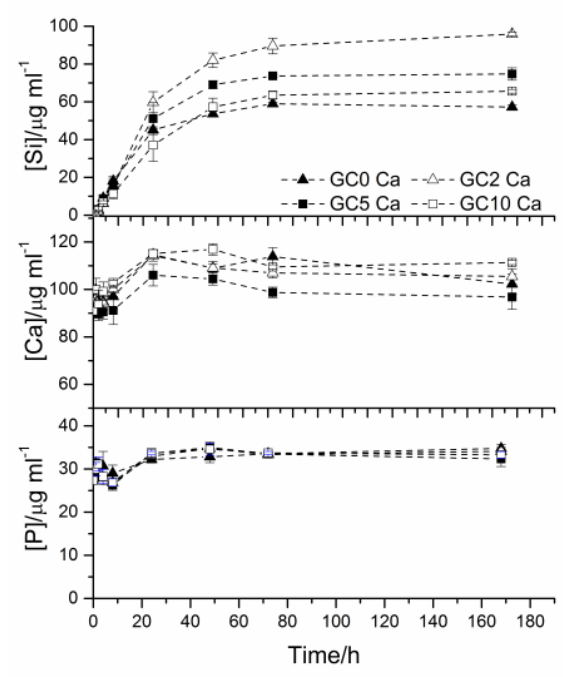

Fig. 8 Concentration profiles of elements in the SBF following immersion of the hybrids made with calcium, $50 \mathrm{wt} \%$ organic and GC values of $0,2,5$ and 10, as a function of time.

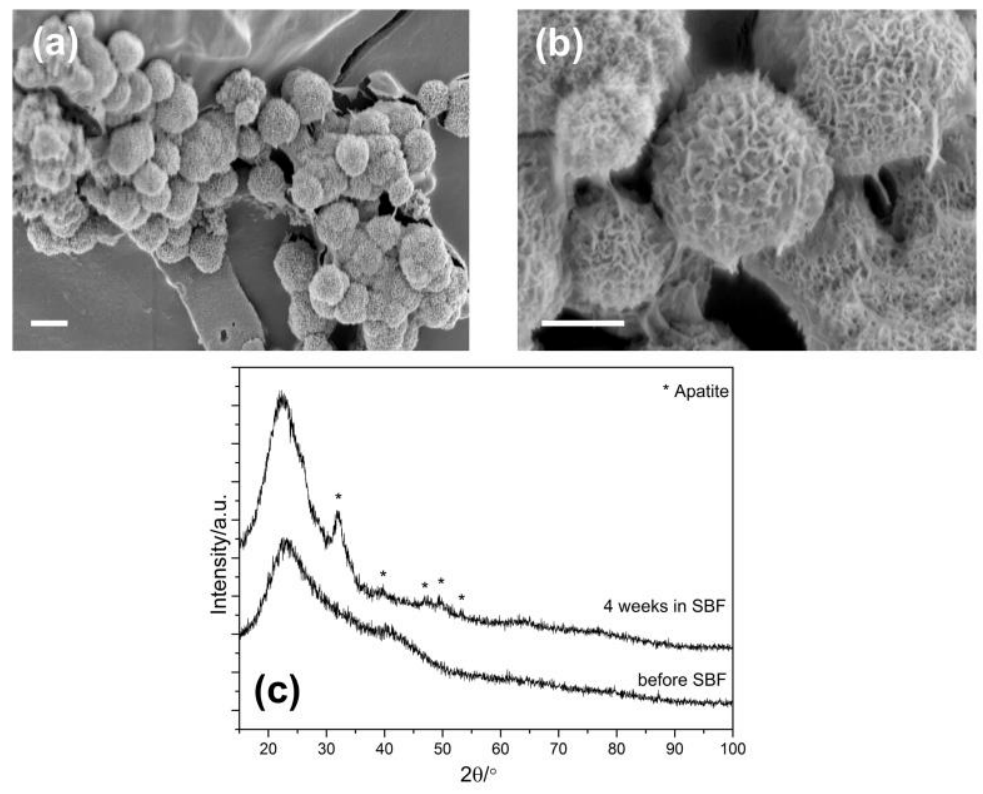

Fig. 9 a, b) SEM images of hybrids with $50 \mathrm{wt} \%$ organic and GC $=5$ after 4 weeks in SBF, showing formation of and HA-like phase on the surface with typical "cauliflower morphology"; a) scale bar $2 \mu \mathrm{m}$ ); b) scale bar $1 \mu \mathrm{m}$; c) XRD pattern showing apatite phase diffraction peaks. 


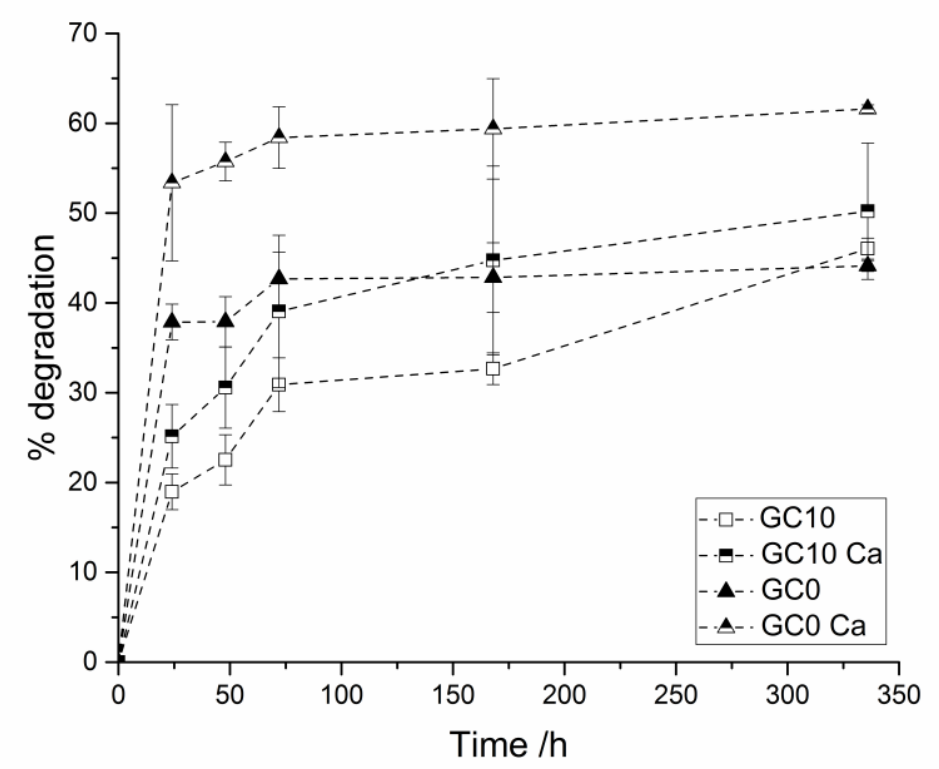

Fig. 10 Weight loss profiles of hybrids (50 wt\% organic) prepared without coupling (GC0) and with GPTMS (GC10), with and without calcium.
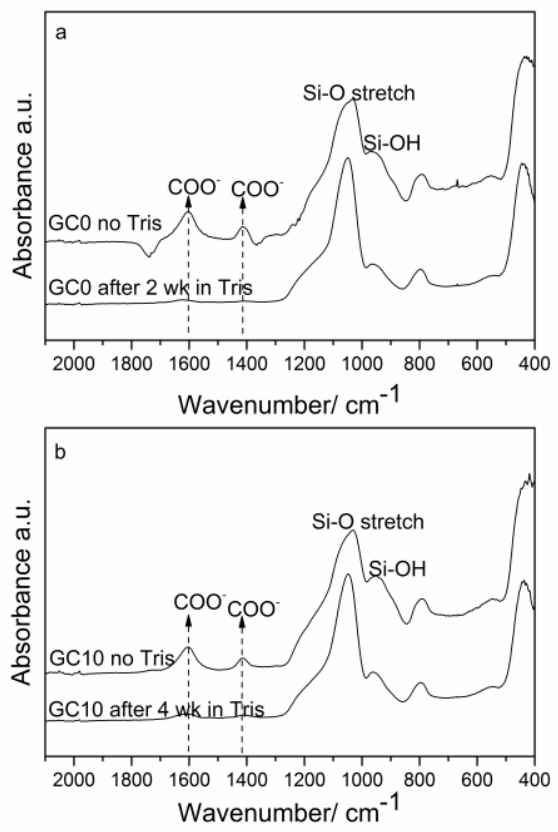

Fig. 11 FTIR of hybrid monoliths made with $50 \mathrm{wt} \%$ organic before and after dissolution in TRIS buffer a) hybrid without coupling to GPTMS; b) hybrid with GPTMS GC $=10$. 


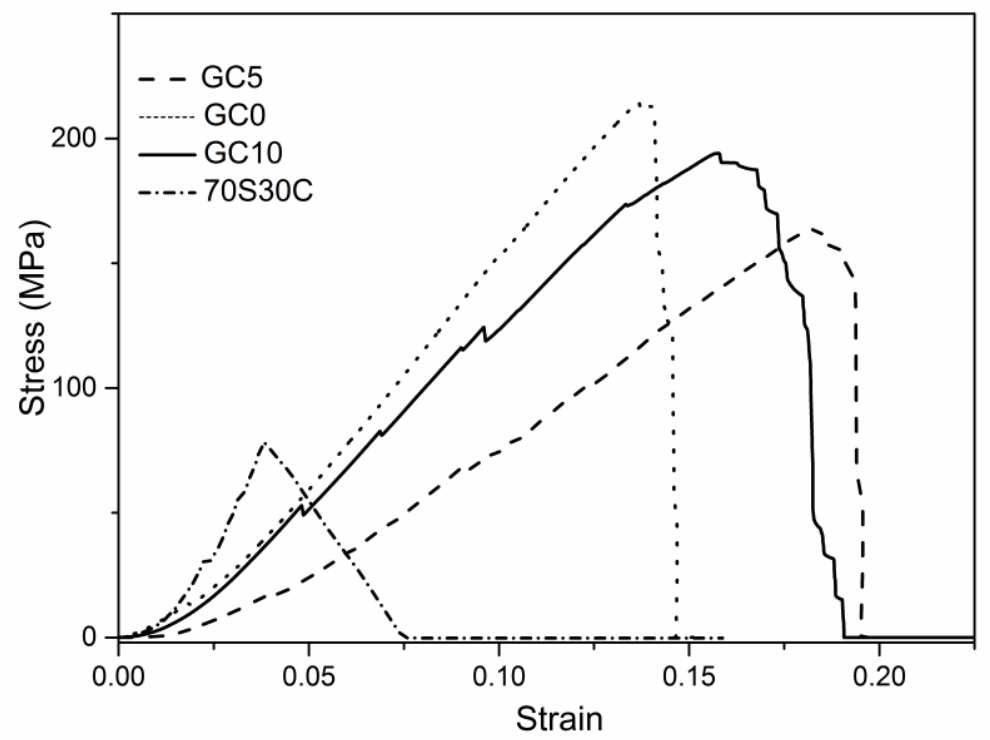

Fig. 12 Compressive stress - strain curves comparing the mechanical behaviour of silica / alginate monoliths containing $50 \mathrm{wt} \%$ organic $(\mathrm{GC}=0,5$ and 10$)$ with $70 \mathrm{~S} 30 \mathrm{C}$ bioactive glass monolith prepared by sol-gel.

Table 1 Percentage abundance of silicate species present in hybrids prepared with $50 \mathrm{wt} \%$ organic and $\mathrm{GC}=2,5$ and 10 .

\begin{tabular}{ccccccc}
\hline Sample & $\mathrm{Q}^{4}$ & $\mathrm{Q}^{3}$ & $\mathrm{Q}^{2}$ & $\mathrm{~T}^{3}$ & $\mathrm{~T}^{2}$ & $\mathrm{D}_{\mathrm{c}}$ \\
\hline 2GC & $53 \pm 2$ & $27 \pm 2$ & $4 \pm 1$ & $10 \pm 1$ & $6 \pm 1$ & $89 \pm 3$ \\
$5 \mathrm{GC}$ & $58 \pm 2$ & $29 \pm 2$ & $8 \pm 1$ & $1 \pm 1$ & $4 \pm 1$ & $87 \pm 3$ \\
10GC & $62 \pm 2$ & $30 \pm 2$ & $8 \pm 1$ & N/A & N/A & $89 \pm 3$
\end{tabular}

Table 2 Mechanical properties of alginate-silica hybrid monoliths (Mean $\pm \mathrm{SD}, \mathrm{n}=5$ )

\begin{tabular}{cccc}
\hline Sample & $\begin{array}{c}\text { Compressive strength } \\
(\mathbf{M P a})\end{array}$ & $\begin{array}{c}\text { Compressive modulus } \\
(\mathbf{G P a})\end{array}$ & Strain at failure (\%) \\
\hline GC0 & $242 \pm 25.01$ & $2.68 \pm 0.05$ & $12.03 \pm 1$ \\
GC5 & $162 \pm 38.33$ & $2.0 \pm 0.2$ & $15.85 \pm 1$ \\
GC10 & $131.85 \pm 6.46$ & $1.28 \pm 0.13$ & $18.35 \pm 2$
\end{tabular}

